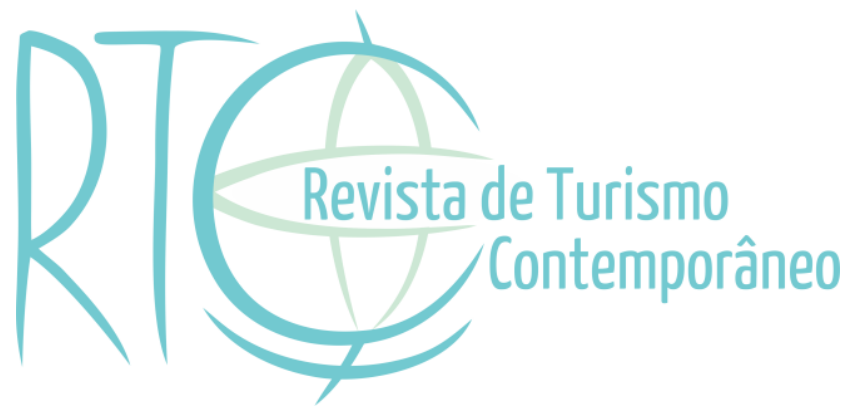

\title{
A importância dos stakeholders para o brand equity e o valor da marca: um estudo de caso da agência/operadora de viagens
}

\section{The importance of stakeholders to brand equity and brand value: a travel agency / travel case study}

\section{Lívia Kubo}

Bacharel em Turismo pela Escola de Comunicações e Artes da Universidade de São Paulo USP, São Paulo/SP, Brasil

E-mail: liviagkubo@gmail.com

\section{Benny Kramer Costa}

Professor do Programa de Pós-graduação em Administração da Universidade N ove de Julho - PPGA/UNINOVE, Osasco/SP, Brasil

Professor Associado do Departamento de Relações Públicas, Propaganda e Turismo da Escola de Comunicações e Artes da Universidade de São Paulo - USP, São Paulo/SP, Brasil

E-mail: bennycosta@yahoo.com.br

\section{Marcos Vinicius Cardoso}

Professor Doutor da Universidade Anhembi Morumbi - UAM, São Paulo/SP, Brasil

E-mail: mvcardoso@uni9.pro.br

\section{Thiago de Luca Sant'ana Ribeiro}

Mestrando em Administração pelo Programa de Pós-Graduação em Administração da Universidade Nove de Julho - UNINOVE, Osasco/SP, Brasil

E-mail: thiago_delucka@hotmail.com 


\section{RESUMO}

A marca é um importante ativo intangível das empresas que nas últimas décadas tem adquirido muita força no mundo dos negócios. Neste contexto, brand equity torna-se um importante conceito para o estudo das percepções, associações e comportamentos com relação à marca, que contribui também para o valor da marca (brand value). $\mathrm{O}$ presente trabalho objetiva explorar as múltiplas relações dos stakeholders e suas contribuições para geração de brand equity e valor da marca no campo do Turismo, mediante a aplicação do modelo de stakeholder de brand equity e valor da marca de Jones (2005), à agência/operadora de viagens. Os resultados do estudo de caso foram ao encontro da literatura, em que os consumidores aparecem como os principais stakeholders para geração de brand equity, mas mostraram que os resultados finais de desempenho da marca só ocorrem por meio da soma das relações com diversos outros grupos-chave, cada um com sua importância em critérios específicos.

Palavras-chave: Brand Equity. Valor da Marca. Stakeholders.

\section{ABSTRACT}

The brand is an important intangible asset from the companies that in the last decades have acquired much force in the business world. In this context, brand equity takes part as an important concept to the studies of perceptions, associations and behaviors related to the brand, which also contributes to the brand value. The present work has the goal to explore the multiple stakeholders' relations and their contributions to the generation of brand equity and brand value in the Tourism field, through the application of the stakeholder model of brand equity and brand value of Jones (2005), to the travel agency/operator. The results of the case study had met the literature, wherein the customers were really the main stakeholders to the generation of brand equity, but they revealed that the final results of the brand's performance only happen through the sum of relations with other key groups, each one with your importance in particular criteria.

Keywords: Brand equity. Brand value. Stakeholders. 


\section{INTRODUÇÃO}

Os segmentos da economia perceberam que a conscientização da marca, a percepção de qualidade, a fidelidade do cliente e as fortes associações da marca, bem como sua personalidade, são extremamente necessárias para se competir no mercado (Aaker \& Joachimsthaler, 2000).

Para os consumidores, as marcas podem simplificar a escolha, comprometer-se com um nível de qualidade em particular, reduzir riscos, gerar confiança e até refletir a completa experiência que os consumidores têm com produtos (Keller \& Lehmann, 2006). Muitas empresas entendem que o nome da marca e o que ela representa é o seu ativo mais importante (Aaker, 1991). Para estas organizações, há muitas vantagens em se ter uma marca valorizada no mercado. Esses benefícios podem ser traduzidos como melhor percepção do desempenho do produto, maior fidelidade, menor vulnerabilidade às ações de marketing da concorrência, maiores margens, menor sensibilidade do consumidor aos aumentos de preços, mais eficácia das comunicações de marketing, oportunidades adicionais de extensão de marca, entre outros (Kotler \& Keller, 2006).

Tem se tornado cada vez mais claro para as empresas que o branding e a construção da marca devem estar focadas no desenvolvimento de valor da marca (brand value) (Guzmán, 2004), especialmente por meio do brand equity, conceito que emergiu a partir dos anos 80 que tem sido uma das prioridades de pesquisa no marketing (Gill et al., 2007). Apesar de ser um complexo conceito, com diversas conceituações na literatura e diferentes estudos descrevendo este ativo intangível (Christodoulides \& de Chernatony, 2010), há pelo menos um consenso geral em que o brand equity denota o valor agregado dotado pela marca ao seu produto (Farquhar, Han \& Ijiri, 1991), por isso sua importância para as empresas.

Ao longo dessas últimas três décadas, as discussões de marcas e brand equity têm se preocupado quase que exclusivamente com os mercados consumidores, seguindo uma abordagem predominantemente "outside-in", em que seus autores defendem que o brand equity se origina do conhecimento da marca pelos compradores (Keller, 2003). No entanto, o panorama em que as organizações globais competem foi remodelado (Wang \& Bezawada, 2011 apud Menon \& Menon 1997); agora a noção de cidadania global demanda que as empresas foquem e equilibrem os interesses de múltiplos stakeholders (Wang \& Bezawada, 2011 apud Waddock \& Smith, 2000). Este conceito não é apenas útil, mas também poderoso, ao examinar e explicar as relações e criações de valor em todas as relações de mercado; refletindo uma importante tendência no mundo dos negócios, de que o valor da marca no 
geral não é apenas criado mediante uma relação a dois, entre a marca e o consumidor; mas é uma construção multifacetada que é afetada por, ou pela soma de, uma gama de relações (Jones, 2005), neste caso, envolvendo outras partes interessadas.

O termo brand equity, no geral, ainda é um tema recente e está em constante desenvolvimento, possuindo diversas abordagens, dentre elas a dos stakeholders, que trataremos neste trabalho. Neste sentido, observa-se a importância de se discutir e explorar o tema para ajudar no desenvolvimento das empresas, em especial da área de turismo.

Neste contexto o problema de pesquisa pode ser expresso a partir do seguinte questionamento: Como as relações e priorizações de stakeholders criam brand equity e valor para a marca?

Assim, o objetivo deste trabalho consiste em analisar de que forma as relações e priorizações de stakeholders criam brand equity e valor para a marca, à luz do modelo de stakeholders de Jones (2005), em uma agência/operadora de viagens. Para atingi-lo utilizou-se um estudo de caso único pelo fato da pesquisa se caracterizar como exploratória.

Os principais achados apontam que os consumidores aparecem como os principais stakeholders para geração de brand equity, mas mostraram também que os resultados finais de desempenho da marca só ocorrem por meio da soma das relações com diversos outros gruposchave, cada um com sua importância em critérios específicos.

A realização deste trabalho busca novas ideias e análises sobre a criação de brand equity e valor da marca sob a abordagem dos stakeholders na área do Turismo, e se faz importante por apresentar uma contribuição inicial para a literatura acadêmica sobre a intersecção destas variáveis. Os resultados gerados neste trabalho poderão ser utilizados tanto para que empresas possam comparar e analisar suas estratégias de relacionamento com seus stakeholders em prol da marca, quanto para que outros estudos do gênero possam ser pensados e desenvolvidos, sempre buscando melhorias e novas compreensões.

\section{REVISÃO DA LITERATURA}

\subsection{Marca}

De acordo com Kapferer (2005), um dos principais pontos de desacordo entre os especialistas é a definição do termo marca; cada estudioso possui sua própria definição. As diferentes abordagens para sua definição decorrem a partir de diferentes filosofias, propósitos, características e perspectivas de stakeholders, ou seja, uma marca pode ser definida, por 
exemplo, a partir da perspectiva dos consumidores e/ou do ponto de vista do proprietário da marca (Wood, 2000).

Alguns autores consideram a criação e a construção de uma marca como sendo um dos principais objetivos de uma empresa, considerando que ela pode ser fonte de vantagem competitiva, se for capaz de efetivamente diferenciar o produto da empresa do restante do mercado (Aaker, 2004; Porter, 2004). Uma marca forte no mercado permite à empresa desenvolver níveis de lealdade junto ao público consumidor que dificultam a migração do seu consumo para outras marcas, às vezes mais baratas (Aaker, 1991).

A marca oferece não apenas uma fonte de informação, revelando assim os seus valores, mas executa algumas outras funções que justificam a sua atratividade e seu retorno monetário - como, por exemplo, um price premium, ou em outras palavras, um preço mais elevado - quando elas são valorizadas pelos compradores (Kapferer, 2005).

Ambler (1992) adota uma abordagem mais orientada para o consumidor, na definição de uma marca como "a promessa de um conjunto de atributos que alguém compra e que proporciona satisfação; [...] os atributos que compõem uma marca podem ser reais ou ilusórios, racionais ou emocionais, tangíveis ou intangíveis”. Estes atributos emanam de todos os elementos do marketing mix e de todas as linhas de produtos da marca. Os atributos estão sujeitos à interpretação do consumidor, sendo altamente subjetivos (Wood, 2000).

A marca é o ponto focal para todas as impressões positivas e negativas criadas pelo consumidor ao longo do tempo em que ele entra em contato com o produto, o canal de distribuição, os funcionários e a comunicação. Assim, ao concentrar todos seus esforços de marketing em apenas um nome, a marca adquire uma aura de exclusividade e se torna um sinônimo de qualidade (Kapferer, 2005).

\subsection{Brand equity}

De acordo com Feldwick (2002), a origem exata do termo brand equity não é clara, mas aparece em alguns estudos no início dos anos 80 e ganhou maior ênfase a partir de 1988 quando o Marketing Science Institute realizou um seminário específico sobre o tema, o que proporcionou definitivamente maior credibilidade ao termo. A partir de então, muita atenção tem sido devotada ao conceito de brand equity (Keller, 1993). Há pelo menos algum consenso em que, segundo Farquhar, Han e Ijiri (1991), o brand equity denota o valor agregado dotado pela marca ao produto (Christodoulides \& de Chernatony, 2010). Este 
conceito foi a primeira definição de brand equity e depois dela, outras definições apareceram (Guzmán, 2004).

A definição mais conhecida é a de Aaker (1991), que descreve o brand equity como "um conjunto de ativos e passivos ligados a uma marca, seu nome e símbolo, que se somam ou se subtraem do valor proporcionado por um produto ou serviço para uma empresa ou para os clientes dela". Se o nome ou símbolo da marca mudar, alguns ou até todos os ativos ou passivos poderão ser afetados e até perdidos, apesar de alguns poderem ser deslocados para o novo nome ou símbolo (Aaker, 1991). O autor ainda defende que os ativos e passivos podem ser agrupados em quatro principais categorias: lealdade à marca, consciência da marca, qualidade percebida e associações da marca. Uma quinta categoria pode também ser agregada como outros ativos da marca, como patentes, marcas registradas e relações com distribuidores. Este autor contribui a uma nova perspectiva do brand equity ao relacionar os consumidores ao ganho financeiro da empresa detentora da marca, complementando ainda que o termo em questão seria a agregação de todos os padrões de atitudes e comportamentos acumulados na mente dos consumidores, canais de distribuição e agentes influentes que aumentam futuros lucros e fluxo de caixa de longo prazo.

De acordo com Keller (1993), existem duas motivações gerais para o estudo do brand equity: uma é a motivação financeira, para estimar o valor da marca mais precisamente com propósitos contábeis - em termos de avaliação de ativos para o balanço patrimonial - ou aquisições ou fins de alienação. A segunda razão para o estudo do brand equity surge de uma estratégia baseada na motivação em melhorar a produtividade do marketing, direcionando seu foco então para o público consumidor e seu comportamento. Assim, a partir dos anos 2000 alguns autores (Keller, 2003; Guzmán, 2004; Keller \& Lehmann, 2006) desenvolveram e aprofundaram a ideia de que o brand equity tem sido estudado por acadêmicos de três principais perspectivas: a financeira, a baseada no cliente/consumidor e a baseada na empresa.

A partir destas três abordagens principais, muitas outras perspectivas foram derivadas ou desenvolvidas. A mais importante delas, e importante para este trabalho, é o Brand equity Corporativo, o qual Keller (2000) define como a "resposta diferenciada por parte dos consumidores, clientes, funcionários, outras empresas, ou qualquer constituição relevante para as palavras, ações, comunicações, produtos ou serviços fornecidos por uma entidade de marca corporativa identificada", que leva em conta todos os outros grupos relacionados a empresa, não somente os clientes. De acordo com Keller (1993), conceituar o brand equity 
por esta perspectiva é útil, pois sugere caminhos específicos para as estratégias e para a área do marketing, sendo uteis em auxiliar a tomada de decisão dos gestores.

Independente da abordagem deste conceito, um alto brand equity é considerado uma vantagem competitiva, pois pode implicar nas seguintes possibilidades para as empresas: cobrar um preço mais caro, aumentar a demanda dos consumidores, tornar mais fácil a extensão de marca, as campanhas de comunicação ficam mais efetivas, há maior aproveitamento comercial, ascensão das margens de lucro e tornar menos vulnerável a competição (Guzmán, 2004).

\subsection{Stakeholders}

O uso do termo stakeholder surgiu do trabalho pioneiro dos acadêmicos do Stanford Research Institute (SRI International) na década de 1960 (Freeman, 1984; Freeman \& Mcvea, 2001; Preble, 2005). Não há muita discordância sobre que tipos de entidades podem ser stakeholders; pessoas, grupos, vizinhanças, organizações, instituições, sociedades, e até mesmo o ambiente natural são geralmente considerados para classificar como atuais ou potenciais stakeholders (Mitchell, Agle \& Wood, 1997). O termo se refere a pessoas, grupos ou organizações que devem, de alguma forma, ser levados em conta pelos líderes, gestores e equipe do front line (Bryson, 2004).

A teoria dos stakeholders tem sido uma popular heurística para descrever o ambiente de gestão por anos, mas ainda não atingiu seu status teórico completo (Mitchell, Agle \& Wood, 1997). Jones e Wicks (1999), por exemplo, listam quatro principais afirmações comuns ao núcleo da teoria dos stakeholders: a empresa possui relações com grupos constituintes (stakeholders); os processos e resultados associados a estas relações baseiam-se em interesses; os interesses de todos os stakeholders legítimos têm valor; o foco da teoria dos stakeholders se encontra na tomada de decisão gerencial (Kakabadse et al., 2005).

Donaldson e Preston (1995) dividiram a literatura em três diferentes abordagens: descritiva, instrumental e normativa. Freeman (1999) deu um panorama geral e resumido sobre as três, afirmando que a teoria descritiva nos diz como o mundo realmente é, descreve comportamentos corporativos; a teoria normativa prescreve como o mundo deveria ser e a teoria instrumental liga os meios e os fins, identifica conexões, é um instrumento para alcançar os resultados esperados, principalmente a rentabilidade (Kakabadse et al., 2005). 


\subsection{Modelo stakeholder de brand equity/valor da marca de jones (2005)}

Com relação ao brand equity, o conceito de stakeholders dá um quadro muito mais rico de fontes de valor da marca. Este conceito nos obriga a examinar a gama de relações em que a marca está envolvida, e reconhecer que o brand equity, ou o valor para os consumidores e stakeholders, é criado por meio de relações múltiplas. A abordagem dos stakeholders não só é uma importante ferramenta para o gerenciamento desses relacionamentos, como também uma ferramenta para fornecer uma visão geral dos negócios, ajudando a priorizar as relações que são estrategicamente importantes.

A abordagem dos stakeholders estimula a identificação de quais stakeholders podem afetar ou ser afetados pela conquista dos objetivos da corporação. Nos termos de brand equity, isto considera o leque de stakeholders que afetam a criação - e destruição - do valor da marca e a natureza dessas relações (Jones, 2005).

Assim, Jones (2005), desenvolveu um modelo de stakeholder brand equity/valor da marca para ser usado como ferramenta para os gestores de marca avaliarem as relações dos múltiplos stakeholders com a marca e entenderem as fontes de valor que provém desta ligação.

O autor afirma que cada relação independente entre stakeholders pode afetar os outros stakeholders, afetando o brand equity individual de cada stakeholder e o geral da marca; ao mesmo tempo em que é possível observar cada relação de forma independente, todos eles estão conectados em termos de brand equity, pelo ponto central da marca.

No modelo são realizadas seis análises principais:

\section{(1) Identificação dos stakeholders e sua importância para a marca}

É a identificação dos diversos grupos de stakeholders e classificação entre primários ou secundários. O conceito de primário e secundário relaciona-se a contribuição do stakeholder para a agregação de valor a marca, sendo eles estáveis e decisivos ou secundários (emergindo apenas em questões específicas).

\section{(2) Identificação do valor das relações e sua priorização}

É a identificação e priorização dos stakeholders de acordo com o tipo de relação que eles têm com a empresa. Baseado nas variáveis de dependência, importância estratégica, atualidade e atratividade, e como por meio destas variáveis os stakeholders contribuem para a geração de brand equity e consequentemente do valor da marca.

\section{(3) Identificação da natureza das trocas e expectativas}


É a identificação da natureza das trocas baseadas em trocas funcionais, trocas simbólicas e trocas hedônicas. As funcionais referem-se à transferência de produtos e serviços, envolvem os valores monetários inerentes a esta operação; refere-se à troca de valor utilitário entre a marca e seus parceiros de relacionamento. Benefícios funcionais dizem respeito à relação preço-qualidade e/ou custo-benefício e o quanto a marca pode ser usada para resolver um problema funcional para seu stakeholder. As trocas simbólicas acontecem em mercados em que a imagem e a reputação são extremamente importantes. Os produtos encantam pelos significados figurativos que eles expressam. Estas trocas costumam ocorrer principalmente pela transferência de significado entre a marca e os consumidores. Trocas hedônicas: referemse às trocas que despertam emoções subjetivas, como nostalgia, conforto, prazer, e assim por diante, que apelam para o senso interior experiencial e sensorial do stakeholder, principalmente do consumidor.

As trocas envolvem também as expectativas de cada stakeholder, ressaltando a importância de analisar quais estão sendo atendidas ou não e por que, e como melhorar para atendê-las. No decorrer do tempo, novos stakeholders podem surgir e novas prioridades podem ser redefinidas.

\section{(4) Identificação da experiência da comunicação total}

Esta etapa reflete como a comunicação suporta e afeta essas relações, e como poderia melhorar para influenciar positivamente o brand equity e o valor da marca. Inclui o comportamento de liderança e seu desempenho da empresa, as formas controladas de comunicação e formas não controladas de comunicação (comunicações de terceiros).

\section{(5) Identificação dos resultados dessas relações}

É a identificação dos resultados provenientes das trocas, relações e comunicações entre a organização e seus stakeholders, além dos resultados gerados pela criação do brand equity para todos seus stakeholders. Os resultados são observados sob a perspectiva da rentabilidade, reputação, lealdade, sinergia e influências políticas.

(6) Identificação da influência de fatores ambientais externos na criação final de valor da marca

Por mais que as relações entre organização e stakeholders possam estar ocorrendo de forma satisfatória e produtiva, gerando alto brand equity para todos os stakeholders e bom desempenho para a empresa, fatores externos podem afetar os resultados dessas relações e influenciar no valor final da marca. Para isso, analisam-se questões que fogem ao controle da 
organização e seus stakeholders, como macroeconômicas, políticas, jurídico-legislativas e questões geográficas e climáticas.

Figura 1: Modelo stakeholder de brand equity e valor da marca.

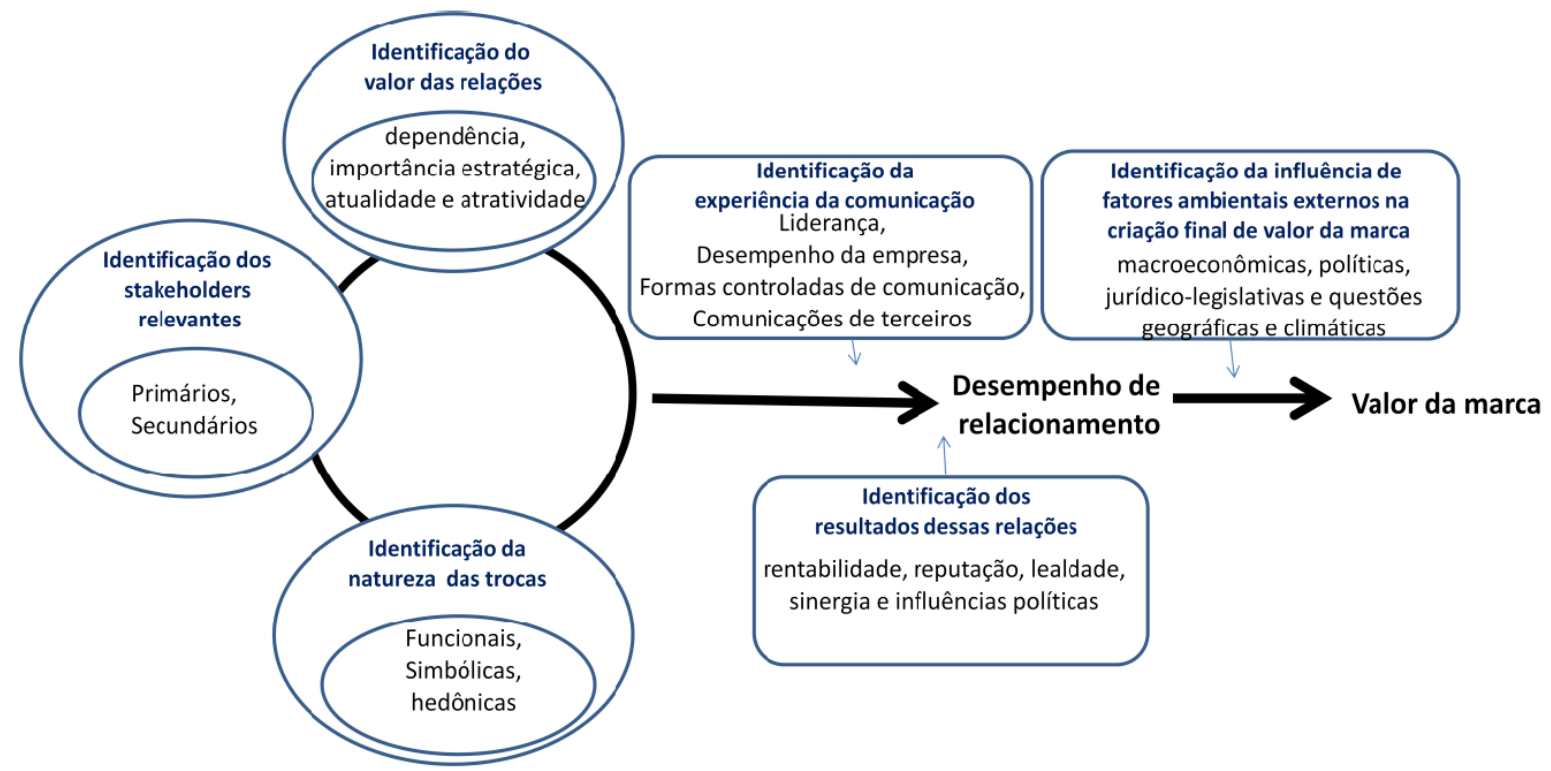

Fonte: Elaborado pelos autores (Base em Jones) - 2005.

\section{METODOLOGIA DE PESQUISA}

Esta pesquisa possui caráter exploratório, de abordagem qualitativa, o que permite o aprofundamento do assunto e proporciona maior familiaridade com o problema de pesquisa. Com relação aos seus procedimentos técnicos, aplicou-se a metodologia de estudo de caso único, utilizando como referência uma empresa turística, denominada a partir de agora por motivos de sigilo como "EMPRETUR”, do ramo de agências/operadoras de viagens.

A EMPRETUR está inserida do ramo de agências e operadoras de viagens desde 1992, sob o nome de Ásia Online, com viagens culturais. O "carro-chefe" da empresa são as viagens em grupo com especialistas, cujos roteiros são desenvolvidos especificamente para cada proposta de viagem em conjunto com estes parceiros, que têm as mais diversas formações e especializações profissionais. É conhecida como uma das cinco melhores operadoras voltadas para o turismo de luxo.

A abordagem qualitativa foi escolhida visando destacar características não observadas e não alcançáveis por meio de um estudo quantitativo (Raupp \& Beuren, 2006). Optou-se pelo estudo de caso para esta pesquisa por esta representar, no geral, a estratégia preferida quando se colocam questões do tipo "como" e "por quê". E quando o pesquisador 
tem pouco controle sobre os eventos e o foco se encontra em fenômenos contemporâneos inseridos em algum contexto da vida real. O estudo de caso permite uma investigação para se preservar as características holísticas e significativas dos eventos da vida real (Yin, 2001). A presente pesquisa utilizou-se do estudo de caso único, ou seja, analisa-se apenas um objeto de estudo visando determinar se as proposições de uma teoria são corretas, ou se algum outro conjunto alternativo de explanações possa ser mais interessante ou adequado (Yin, 2001).

Para buscar a resposta da questão levantada neste trabalho, definiu-se que seriam realizadas cinco entrevistas com atuais funcionários da EMPRETUR Viagens de Conhecimento, no período de 26-05 a 06-06-2014. Apesar de ser uma pequena amostra, ela apresenta uma extensa e profunda análise do assunto e objeto estudado, fornecendo detalhado material que tornou viável cruzamento de dados, análise e conclusão da pesquisa.

Para isso, elaborou-se um roteiro de entrevistas baseado no problema de pesquisa e no modelo teórico de Jones (2005) que este trabalho se propôs analisar. O roteiro se constituiu de um total de 21 questões abertas, a maioria delas contendo subquestões para o aprofundamento e melhor exploração do assunto. Antes da aplicação das entrevistas, foi realizado um pré-teste com outros executivos do setor turístico; com a função de revelar problemas do plano do estudo, das questões ou das habilidades de pesquisa (Yin, 2001), o que foi pertinente e útil para a reformulação e a otimização de algumas questões.

\section{ANÁLISE E DISCUSSÃO DOS RESULTADOS}

As análises foram divididas em dois tipos: análise do perfil dos entrevistados e análise e discussão dos resultados organizacionais. A primeira verifica informações referentes a tempo de atuação na empresa; função exercida dentro da empresa e grau de escolaridade. Com relação a segunda, os resultados da pesquisa foram divididos em função de cada etapa e atributos levantados no modelo stakeholder de brand equity/valor da marca de Jones (2005), sendo eles: (1) Identificação dos stakeholders e sua relevância para a marca; (2) Identificação do valor das relações e sua priorização; (3) Identificação da natureza das trocas e expectativas; (4) Identificação da experiência da comunicação total; (5) Identificação dos resultados dessas relações e (6) Identifição da influência de fatores ambientais externos na criação final de valor da marca. 


\subsection{Análise e discussão dos resultados organizacionais}

\section{(1) Identificação dos stakeholders e sua relevância para a marca}

Foram identificados os seguintes stakeholders: empresas consolidadoras de passagens aéreas e as próprias companhias aereas, pelo entrevistado do departamento aéreo; os terceirizados que contribuem com o material de viagem, impressões, brindes, e os que fazem serviços de entrega como motoboys e Correios, no caso dos entrevistados de Atendimento \& Vendas e Operações; os bancos e instituições financeiras que apoiam nas remessas internacionais e câmbios de moeda, mencionado pela Gerência-geral e todos estes foram incluídos no grupo "fornecedores".

Todos os entrevistados destacaram e mostraram consciência de que os principais fornecedores eram os DMCs (Destination Management Company), ou em outras palavras, os operadores locais em cada destino que a EMPRETUR atua. Estes seriam os principais fornecedores, os complementares seriam comentados apenas em casos específicos.

Outros três stakeholders foram identificados por todos: revendedoras e intermediárias entre a EMPRETUR e os clientes; os especialistas, e as parcerias institucionais que a EMPRETUR possui com a Casa do Saber e a Pinacoteca do Estado de São Paulo.

No que tange à categorização dos stakeholders entre primários ou secundários para a contribuição de valor a marca EMPRETUR as respostas foram quase unânimes: primários seriam os proprietários, funcionários, fornecedores, clientes, especialistas e parceiros; e secundários seriam os concorrentes, governos e órgãos reguladores, mídia, ONGs e projetos, associações do setor, sociedade e agências de viagens.

Os proprietários foram considerados primários devido a grande participação e atuação deles na empresa, desde o investimento de capital, definição dos valores, missão e posicionamento da empresa, tomada de decisões, até a operação de certas viagens. Resultado que vai ao encontro das idéias de Kam et al. (2010), onde a atenção da administração deve ser focada para a área do branding interno: ao tornar o conceito da marca bem compreendida dentro da empresa de serviços, a mensagem da marca torna-se um dispositivo interno coeso que orienta as atividades da marca dentro da organização.

Os funcionários, seguindo a linha de raciocínio dos entrevistados, são aqueles que captam essa missão, valores e intenções e as executam, devendo estar alinhados e compartilhando das mesmas idéias e propósitos.

Já os fornecedores devem ser cuidadosamente selecionados, devendo já ter intrínsecos em seus serviços os valores e missões semelhantes com os da EMPRETUR. São 
eles que representam a EMPRETUR no momento da entrega do serviço, portanto são absolutamente importantes para a criação de brand equity e valor da marca para a empresa. Os clientes, por sua vez, também foram considerados decisivos pelos entrevistados, por serem os receptores finais e a opinião final sobre o produto. Como apresentado na literatura são essenciais sua satisfação e expectativas atendidas para criação de brand equity e valor da marca (Aaker, 1991, Feldwick, 1996 \& Keller, 2003).

Com relação aos especialistas, todos os cinco entrevistados ressaltaram que são uma marca registrada da EMPRETUR e fortes contribuidores de valor para a marca. Para os entrevistados, muito semelhante é a participação das parcerias, uma vez que grande parte dos especialistas chegou a EMPRETUR via Casa do Saber, Pinacoteca e outras instituições.

Os concorrentes foram os únicos stakeholders que causaram certa divisão de opiniões entre os entrevistados. Enquanto alguns consideraram secundários, pelo fato da EMPRETUR não ter relações diretas e ativas com eles, e por acharem que os concorrentes não afetam o valor da marca EMPRETUR, outros consideraram primários, pelo fato da influência indireta.

Outros stakeholders, como associações, ONGs, governo e órgãos reguladores, agências de viagens, foram definidos como secundários. A mídia curiosamente foi citada por todos como secundária pelo fato de ter pouca expressividade nos negócios da EMPRETUR e que deverá ser mais explorada no futuro.

Quanto a relevância para a marca, três stakeholders devem ser destacados. Os parceiros fornecedores localizados nos destinos turísticos que apresentam em seu portfólio de produtos e serviços um conjunto diversificado de alta qualidade de itens, nos aspectos gastronômicos, culturais, de hospitalidade e de lazer, voltados para a clientela da empresa que preza por experiências ímpares e distintas. Os clientes são importantes não só pelos seus feedbacks de experimentações, produtos e serviços, como também por realizar a divulgação da empresa para clientes em potencial e target superior de mercado. Já os funcionários estabelecem contato com os fornecedores, transmitindo e fazendo a troca de informações para que o produto final seja entregue com excelência. As posturas e condutas dos funcionários ditam a forma como os diversos stakeholders perceberão a empresa.

\section{(2) Identificação do valor das relações e sua priorização}

a) No critério Dependência, com exceção dos parceiros institucionais, todos os stakeholders definidos como primários são os mesmos dos quais a EMPRETUR depende para criação de 
brand equity e valor da marca e encontram-se nesta ordem: fornecedores, funcionários, proprietários, clientes e especialistas.

Já os parceiros institucionais, apesar de serem considerados ativos e relevantes para a marca, não são necessariamente stakeholders que causem uma relação de dependência por parte da EMPRETUR.

b) Quanto a Importância Estratégica, no geral, a ordem de priorização pelo quesito importância estratégica foi a seguinte: clientes, especialistas, fornecedores, funcionários e parceiros, sendo os três primeiros os mais importantes.

c) Em relação a Atualidade, Jones (2005) recomenda verificá-la por meio dos atributos "ativos", "latentes", e “críticos". Como "ativos", os resultados apontam para os proprietários, funcionários, fornecedores, clientes, especialistas e parceiros. Os "latentes"correspondem aos concorrentes, governo e órgãos reguladores, mídia, ONGs e projetos, associações do setor, sociedade e agências de viagens. E por fim, os "críticos" incorporam alguns fornecedores e alguns clientes.

Os concorrentes foram considerados pela maioria como latentes, pelo fato de não manterem relações ativas com a EMPRETUR. Não se teve notícia de nenhum concorrente específico e conhecido causando perdas ou prejuízos a empresa objeto de estudo. Por meio das entrevistas, percebeu-se ainda que a mídia, as ONGs e projetos e as agências de viagens estão latentes quanto as relações com a empresa atualmente, mas todos viram benefícios em torná-las relações ativas em prol da criação de brand equity e valor para a marca.

Vale ressaltar que alguns entrevistados mencionaram a existência de alguns fornecedores em estado atual crítico, por uma diversidade de motivos: pedidos de reembolso, recorrente demora no envio de cotações, recorrente envio de informações ou valores errados e alguns problemas no decorrer da viagem. Alguns problemas são pontuais, como atrasos em transfers, fatos que podem acontecer com qualquer fornecedor. No entanto, alguns fornecedores apresentam problemas recorrentes no local, decorrente da falta de habilidade de trabalhar com mercados com culturas muito diferentes da sua.

d) No tocante a Atratividade, estabeleceu-se a seguinte ordem: clientes, especialistas, parceiros, funcionários, ONGs e projetos. Foi possível perceber que a EMPRETUR capta seus clientes principalmente via indicações, recomendações e boca a boca. Os especialistas ficam em segundo lugar pois existe uma grande relação de troca e mutualidade entre eles e a EMPRETUR, principalmente na questão de atratividade. Segundo os entrevistados, muitos especialistas têm grande reconhecimento, trabalham em renomadas empresas e universidades 
públicas e estão presentes na mídia, como colunistas de jornais e comentaristas de programas de televisão. A mesma linha de pensamento segue para os parceiros institucionais, onde há uma troca mútua de beneficios, gerando atratividade para ambos os negócios. Os funcionários, por sua vez, foram citados como geradores de atratividade a partir do momento que têm uma boa relação com a empresa e são valorizados por ela, passando uma imagem positiva e sincera da empresa aos clientes, fornecedores e demais stakeholders.

As ONGs e projetos também foram vistos como fonte de atratividade, pois boas ações e engajamentos sociais geram identidade e credibilidade. Uma alta responsabilidade social corporativa vai resultar em maior credibilidade corporativa pelos stakeholders da empresa, além de melhorar medidas de percepções do cliente, tais como imagem da marca, notoriedade da marca, preferência da marca, credibilidade da marca, fidelidade à marca, engajamento a marca e positivo boca a boca com relação a ela (Shamma \& Hassan, 2011; Torres et al., 2010).

A priorização do stakeholder cliente, especificamente apresentada nos itens importância estratégica, atualidade e atratividade, além da óbvia razão deste grupo ser o consumidor do produto e, por conseguinte o gerador de lucro para a empresa, também se dá por ser a principal fonte de atratividade para outros clientes e outros stakeholders-chave. Por exemplo, fornecedores renomados que buscam a empresa devido a sua respeitabilidade junto ao cliente, que demanda qualidade superior no mercado. Também, soma-se a importância do stakeholder cliente, o fato deste se constituir em importante fonte de resultados de desempenho da marca como lucratividade/rentabilidade, reputação e lealdade. Outro stakeholder de destaque são os fornecedores, que ficaram em primeiro lugar no quesito dependência, segundo lugar em atualidade e terceiro lugar em importância estratégica. É um resultado muito coerente, uma vez que lidando com clientes de alto nível de exigência e oferecendo viagens exclusivas e personalizadas, os fornecedores devem acompanhar a qualidade dos serviços e produtos entregues.

\section{(3) Identificação da natureza das trocas}

Houve certa insegurança por parte dos entrevistados, que classificaram, em resumo, da seguinte forma: 
Figura 2: Identificação da natureza das trocas

\begin{tabular}{|l|l|l|}
\hline Stakeholders & Categorização & Trocas \\
\hline Proprietários & Funcionais & Financeiras - Informações \\
\hline Funcionários & Funcionais & Financeiras - Serviços \\
\hline Fornecedores & Funcionais & $\begin{array}{l}\text { Produto - Financeiras - } \\
\text { Informações - Serviços }\end{array}$ \\
\hline Clientes & $\begin{array}{l}\text { Funcionais/Simbólicas/ } \\
\text { Hedônicas }\end{array}$ & $\begin{array}{l}\text { Produto - Financeiras - Serviços } \\
\text { - Informações }\end{array}$ \\
\hline Concorrentes & Nenhuma & Informações \\
\hline Governo/Órgãos & Nenhuma & Financeiras - Informações \\
\hline Mídia & Funcionais/Simbólicas & Informações \\
\hline ONGs e Projetos & Funcionais & $\begin{array}{l}\text { Informações - Serviços - } \\
\text { Financeiras }\end{array}$ \\
\hline Associac. Setor & Nenhuma & Informações \\
\hline Sociedade & Simbólicas & Informações \\
\hline Especialistas & Funcionais/Simbólicas & $\begin{array}{l}\text { Financeiras - Serviços - } \\
\text { Informações }\end{array}$ \\
\hline Parceiros Instituc. & Funcionais/Simbólicas & $\begin{array}{l}\text { Financeiras - Serviços - } \\
\text { Informações }\end{array}$ \\
\hline Agências viagens & Funcionais/Simbólicas & $\begin{array}{l}\text { Financeiras - Serviços - } \\
\text { Informações }\end{array}$ \\
\hline
\end{tabular}

Fonte: elaborado pelos autores.

Devido ao fato dos entrevistados terem apenas focado nas trocas entre os stakeholders internos, induziu-se a questão de como trocas simbólicas e hedônicas poderiam ocorrer em relação a estes stakeholders. Diante disto, alguns notaram que a troca simbólica, e até hedônica, poderia ser importante também entre empresa e funcionários. Funcionários que recebem treinamentos sobre certos destinos resalizam trocas simbólicas. Além disso, levantou-se durante a entrevista a informação de que alguns funcionários viajam para conhecer o destino e para montar um novo produto, nota-se que este caso é uma típica troca hedônica, caracterizada pelos sensos experienciais e sensoriais do stakeholder. Esta estratégia esta em linha com o proposto por Gartner (2009) onde cabe a empresa capacitar seus funcionários sobre os significados destes destinos intangíveis para que este saiba prestar a consultoria necessária e tenha a competência de entregar a viagem de forma que o cliente tenha e melhor experiência possível.

Pela análise das respostas, pode-se ainda perceber que os entrevistados não incluíram nenhuma categoria aos concorrentes, governo e órgãos reguladores e associações do setor, o que demonstra pouca relação de troca ativas e efetiva com estes stakeholders.

A pesquisa mostrou que os entrevistados estão bastante alinhados e cientes sobre as expectativas de cada stakeholder. Segundo eles, os proprietários esperam retorno financeiro, boa reputação da empresa no mercado e clientes e funcionários satisfeitos para manter a 
longevidade, crescimento e desenvolvimento a longo prazo da empresa. Os funcionários desejam que a EMPRETUR tenha muitos clientes para que continue crescendo e lhe dando cada vez melhores perspectivas de trabalho, reconhecimento profissional, um bom ambiente de trabalho com uma condução honesta e transparente. Os clientes esperam que a EMPRETUR preste um ótimo atendimento e entregue viagens de alto padrão de qualidade. Apenas um dos entrevistados conseguiu identificar as expectativas, na sua opinião, dos concorrentes, sendo a expectativa de uma concorrência leal e honesta, sem praticar preços predatórios. Ainda segundo as entrevistas, os especialistas e parceiros almejam que a EMPRETUR continue divulgando e promovendo seu nome e proporcione retorno financeiro. Os outros stakeholders não tiveram grande menção durante a entrevista, uma vez que não estabelecem fortes relações com a EMPRETUR.

\section{(4) Identificação da experiência da comunicação total}

Foi possível perceber que a liderança se dá de forma bastante flexível e participativa. Isso ocorre pelo fato da EMPRETUR sempre ter sido uma empresa enxuta, sem a necessidade de uma liderança central. Os proprietários sempre tiveram muita confiança nos funcionários, dando-lhes bastante autonomia. Agora que a empresa está crescendo e criando os primeiros cargos de gerência. A falta de uma liderança mais persuasiva e imperativa pode causar conflitos entre os funcionários, podendo gerar riscos à entrega dos serviços e produtos e consequentemente ao brand equity de outros stakeholders e valor da marca.

No geral, foram identificadas formas controladas de comunicação, sempre partindo da empresa para os demais stakeholders. As ações de marketing também são formas controladas, sendo elas conteúdo do website, malas diretas, newsletters, postagens no facebook, catálogos entre outros. Verificou-se que a empresa deve beneficiar-se disso estando o mais presente possível nestas formas controladas de comunicação, manipulando cuidadosamente os conteúdos que serão recebidos pelos stakeholders externos. Afinal, o meio ambiente externo, com todas as suas informações, incluindo o marketing da empresa, contribuem para o conhecimento da marca (Raggio \& Leone, 2006), que Aaker (1991) e Keller (1993) ligam diretamente a criação de brand equity.

Todos entrevistados concordaram que as formas não controladas seriam a mídia espontânea, ou seja, a mídia não-paga, e o boca a boca dos clientes. No entanto, um entrevistado levantou uma questão pertinente, notou-se que os stakeholders que trabalham diretamente com a EMPRETUR, podem ter suas próprias opiniões e percepções e externá-las para quem quiser, inclusive para os próprios clientes da EMPRETUR durante suas viagens. 
Isso só exemplifica a importância de um bom relacionamento e comunicação da empresa com seus fornecedores.

\section{(5) Identificação dos resultados dessas relações}

a) Em relação a Lucratividade, todos julgaram muito satisfatória a lucratividade da empresa. Prova disso tem sido a possibilidade do crescimento e desenvolvimento da empresa, por meio da recente contratação de novos funcionários e criação de novos departamentos.

Ao serem perguntados sobre como melhorar este resultado mediante uma melhor gestão do relacionamento com os stakeholders, algumas ações foram sugeridas: renegociar as tarifas com os fornecedores mais fiéis; recompensar funcionários que consigam negociar formas de pagamento e boas tarifas com os fornecedor e clientes; investir na mídia e em novas ações de marketing; estreitar relações com agências de viagens estratégicas; buscar novas parcerias com renomados especialistas e instituições de cultura para o aumento da oferta de produtos e atração de novos clientes por meio destes stakeholders-chave.

b) Quanto a Reputação, seus resultados são muito positivos, apesar de só estar tendo maior visibilidade nos últimos anos. Acredita-se que isso se deve ao fato da empresa nunca ter investido em mídia para auto-promoção e por não ter um departamento de Marketing estruturado, o que está sendo criando no presente momento. Os positivos feedbacks recebidos no retorno das viagens também considerados pelos entrevistados são um termometro da reputação da empresa. A parceria com renomados especialistas e instituições como a Casa do Saber e a Pinacoteca do Estado de São Paulo, agrega credibilidade, elevando o brand equity e seu valor da marca. Entre as ações para melhorar a relação com os stakeholders para melhorar a reputação da marca, encontram-se: manter um bom relacionamento, atender às expectativas e dar boas condições de trabalho aos seus funcionários; manter um bom relacionamento com seus fornecedores; sempre estar atento ao mercado, prospectando e agregando novos fornecedores; buscar novas parcerias com renomados especialistas e instituições de cultura; investir em ONGs e projetos, mostrando responsabilidade social, ambiental e cidadania; investir na divulgação das viagens e imbutir seus valores e filosofias como operadora de viagens de conhecimento.

c) No critério Lealdade, a EMPRETUR possui inúmeros clientes leais e o índice de retorno e repetição de viagens é muito grande. O que impede uma fidelização ainda maior é o fato da EMPRETUR não operar muitos destinos, como grande parte dos países da Europa, América 
do Norte e Oceania como um todo. Nas entrevistas, pode-se curiosamente notar que a lealdade também é característica da EMPRETUR com relação aos funcionários. Dois funcionários que saíram da empresa há menos de dois anos retornaram recentemente. Um terceiro funcionario abriu uma outra operadora de viagens e estabelece relações de parceria com a EMPRETUR, enquanto um quarto funcionário, apesar de estar trabalhando em uma empresa de outro ramo, continua realizando trabalhos como free lancer para a EMPRETUR. Tudo isso demonstra o bom relacionamento que a empresa mantém com seus funcionários.

A lealdade dos especialistas e parceiros também é muito grande, os primeiros pelo fato de não haver outra operadora de viagens que ofereça produto parecido, além de ser uma troca muito vantajosa para eles, em questões financeiras e profissionais. Já com relação aos fornecedores, percebeu-se ser dificil estabelecer uma medida de lealdade pois estes prestam os serviços visando basicamente as vendas e o lucro. São normalmente grandes empresas DMCs que possuem inúmeros outros clientes-operadoras de viagem como a EMPRETUR e não há exatamente uma relação de lealdade. As agências de viagens também não demonstram nenhuma lealdade, pois a EMPRETUR nunca fez um trabalho de divulgação do seu trabalho dirigido à elas.

Com relação à uma melhor gestão de relações com stakeholders para melhoria dos resultados de lealdade, encontrou-se nas entrevistas: unir esforços dos stakeholders internos para oferecer sempre as melhores viagens aos clientes; manter boas relações com os funcionários; desenvolver ações de motivação e incentivo ao trabalho dos funcionários, como oferecimento de comissões, participação nos lucros, viagens de inspeção; estabelecer uma relação cordial e profissional como todos os fornecedores; desenvolver um trabalho junto às agências de viagens, oferecendo um preço competitivo para captá-las e fidelizá-las; seguir sempre sua missão e valores pré-estabelecidos e entregar seus produtos e serviços com honestidade, idoneidade e alta qualidade.

d) Quanto a Sinergia, a sinergia interna, ou seja, dos stakeholders internos, como proprietários, funcionários e fornecedores, é satisfatória, todos têm boa vontade e se unem em prol dos objetivos da empresa, mas há muito o que melhorar ainda no quesito do estabelecimento de procedimentos e processos internos. Já com relação à sinergia externa, entre a empresa e todos os stakeholders em geral, tem sido alcançada com sucesso, mantendo fortes relações com alguns stakeholders, gerando bons níveis de brand equity e valor da 
marca. Pela análise das entrevistas, isso pode se relacionar ao quesito do estilo de liderança da empresa, cujos colaboradores a descrevem como "flexível" e "participativa".

O fato da EMPRETUR estar crescendo e se desenvolvendo, inclusive com o aumento do número de funcionários e de novos departamentos, demanda que todos estejam alinhados para que não haja conflitos em ações e linhas de pensamento. Neste momento de reestruturação organizacional interna, é importante ter uma liderança mais rigorosa e atenta para estabelecer regras e garantir o cumprimento igual de todas as elas. A falta de sinergia pode causar conflitos internos e impactar na entrega dos produtos e serviços, refletindo no brand equity de determinados stakeholders.

e) No tocante a Influência política, os entrevistados não souberam citar nenhum resultado de influência política decorrente da gestão de relacionamento com seus stakeholders.

(6) Identificação da influência de fatores ambientais externos na criação final de da marca

Uma questão relevante de fator ambiental externo que impactou nos resultados foi a Copa do Mundo. Ela foi citada pela maioria dos entrevistados por ser o fato mais relevante e recente que tem impactou a empresa. Outra questão relevante levantada foi a globalização e o avanço das tecnologias e da internet. Contexto em que muitos têm acesso a todas informações, como informações sobre destinos, viagens e o mercado turístico.

a) No que se refere a Questões macroeconômicas, a economia geral do país impacta a EMPRETUR, pois quando a economia estagna ou entra em crise, a reação natural das pessoas é parar de consumir bens supérfluos e economizar até que a situação dê perspectivas de melhora. A flutuação do dólar também é bastante impactante, interferindo nas decisões de destino e volume de vendas.

b) Em relação a Questões políticas, Guerras, terrorismo, conflitos políticos, golpes de estado e manifestações contra o governo são alguns dos exemplos que atrapalham as vendas, a logística das viagens em realização e as relações entre empresa e clientes. Pode-se observar como a relação da empresa com seus fornecedores locais é importante neste momento.

c) Sobre as Questões jurídico-legislativas, apenas um dos entrevistados recordou-se de uma decisão da Justiça em fazer uma agência de viagens reembolsar um cliente em $80 \%$ do valor 
total da viagem por uma desistência muito próxima a saída da viagem. Segundo ele, isso na época causou muita polêmica e temor entre as agências de viagens.

d) Quanto as Questões geográfico-climáticas, as maiores preocupações são catástrofes da natureza, como terremotos, tsunamis, furacões, vulcões entre outros, que fazem com que qualquer cliente desista da viagem e com que outros potenciais clientes excluam determinado destino de seus planos.

\section{CONSIDERAÇÕES FINAIS}

Após a realização, análise e discussão dos resultados das entrevistas aplicadas aos cinco colaboradores da empresa, foi possível concluir que muitos stakeholders são indispensáveis e insubstituíveis para a criação de brand equity e valor da marca para a empresa. Cada um com sua importância em determinados critérios específicos, cuja soma de todos os critérios e a soma de todas as relações resulta em um alto brand equity, ou seja, alto valor para os stakeholders, e consequentemente um alto valor da marca, resultando em um alto valor para os proprietários da EMPRETUR.

Os parceiros fornecedores localizados em destinos são extremamente importantes, pois é a intermediação de experimentações, produtos e serviços, que agregam conhecimentos elevador aos seus visitantes, no caso, os clientes da empresa investigada.

Os clientes são também um dos motivos do sucesso da parceria da EMPRETUR com seus especialistas e instituições, como a Casa do Saber e a Pinacoteca do Estado de São Paulo, pois nesta relação entre empresa e parceiros há uma troca mútua de favores, onde para estes stakeholders, a atração de clientes-chave para seus cursos, palestras e negócios são essenciais.

No que tange a valorização das relações e a priorização, observa-se a partir dos resultados, a importância de tornar os fornecedores críticos em ativos, por meio da solução dos problemas, ou até em latentes, com a quebra do contrato ou finalização definitiva da parceria. Assim, pensando no quesito da atualidade, a prioridade de relações foi categorizada em: clientes - transformar os "críticos" em "ativos", fornecedores - transformar os "críticos" em "ativos", mídia - transformar "latente" em "ativo", agências de viagens - transformar "latente" em "ativo", ONGs e projetos - transformar "latente" em "ativo".

As três caracterizações referentes a natureza das trocas se fizeram presentes nas práticas relacionais da empresa com seus stakeholders, quais sejam, "funcionais" pela questão contratual, racional, que enfatizam produtos e serviços adiquiridos e a sua precificação; 
"simbólicas", que diz respeito aos significados figurativos, identificações temáticas e desejos culturais e históricos vivenciados no destino turístico; "hedônico" diz respeito ao estímulo das emoções, como por exemplo, emoções vividas nos filmes de época, em locais naturais ou históricos, onde se realizaram filmagens.

No que se refere a comunicação total, a partir dos resultados, observa-se a necessidade de se constituir mecanismos de direcionamento da comunicação flexível existente na organização, de modo a alinhar os valores implícitos desejados nas informações distribuídas aos diversos stakeholders.

Apesar da EMPRETUR possuir satisfatórios resultados financeiros, a empresa poderia investir em ações de marketing, como propagandas direcionadas ao público-alvo, de alto poder aquisitivo e sensíveis manifestações culturais, alavancando assim a lucratividade e por conseguinte a reputação, lealdade dos clientes e sinergia com os stakeholders.

Por fim, quanto ao objetivo geral deste trabalho, a ideia central é que as relações e priorizações de stakeholders dependem de quão bem a empresa gerencia suas relações com grupos-chave e todos seus stakeholders de uma forma geral, buscando atender às suas expectativas e gerar boas percepções, associações e comportamentos destes stakeholders em relação à marca; isto consequentemente gera bons resultados de desempenho da marca e da empresa, criando um alto valor final a marca. O modelo que foi utilizado para estas comparações se mostrou pertinente, à medida que seus seis componentes puderam ser avaliados neste trabalho.

O modelo proposto por Jones (2005) mostrou-se aplicável a empresa estudada. Suas relações entre stakeholders e o brand equity permitem a empresa a formulação de estratégia mais adequadas as demandas de mercado e a criação de valor de marca. No longo prazo é este valor de marca que gerará maiores retornos para a organização.

Sugere-se como futuras pesquisa a replicação deste estudo tanto em outras agências/operadoras de viagens de luxo, para uma possível comparação de resultados, mas também em outras atividades do Turismo, tais como hotéis, companhias aéreas, DMCs, entre outros, para buscar entender a dinâmica e as características das relações entre empresastakeholder de cada ramo do Turismo. Outra sugestão seria a utilização de outros modelos que não o de Jones (2005), ou até mesmo o desenvolvimento de um modelo exclusivo com outros elementos e variáveis de análise. 
Além disso, apesar das relações entre empresa-stakeholder serem um fenômeno dinâmico e observável, utilizar abordagens metodológicas quantitativas poderiam abrir um campo totalmente novo de exploração para o tema.

\section{REFERÊNCIAS}

Aaker, D. A. (1991). Managing brand equity: capitalizing on the value of a brand name. New York: The Free Press, Simon \& S Inc.

(2004). Brand portfolio strategy. Creating relevance, differentiation, energy, leverage and clarity. New York: The Free Press.

Aaker, D. A., \& Joachimsthaler, E. (2000). Brand leadership. New York: The Free Press, 2000 .

Ambler, T. (1992). Need-to-Know-Marketing, London: Century Business.

American Marketing Association (1995). Resource Library - Dictionary. Recuperado em 15 maio, 2016, de http://www.marketingpower.com/_layouts/Dictionary.aspx?dLetter=B.

Bryson, J. (2004). What to do when stakeholders matter: stakeholder identification and analysis techniques. Public Management Review, 6(1), 21-53.

Christodoulides, G., \& de Chernatony, L. (2010). Consumer based brand equity conceptualization and measurement: a literature review. International Journal of Market Research, 52(1), 43-66.

Donaldson, T., \& Preston, L. (1995). The stakeholder theory of the corporation: concepts, evidence and implications. Academy of Management Review, 20(1), 65-91.

Farquhar, P., Han, J. \& Ijiri, Y. (1991). Recognizing and measuring brand assets. Marketing Science Institute, MA.

Feldwick, P. (2002). What is brand equity, anyway? World Advertising Research Center.

Freeman, R. E. (1984). Strategic management: a stakeholder approach. Boston: Pitman.

Freeman, R. E. (1999). Divergent stakeholder theory. The Academy of Management Review, 24(2), 233-236.

Freeman, R. E., \& Mcvea, (2001). J. A stakeholder approach to strategic management. Darden Business School Working Paper, (01-02).

Gill, R. B., Andr, E. F., Salinas, E. M. (2007). Family as a source of consumer-based brand equity. Journal of Product \& Brand Management, 16(3), 188-199.

Guzmán, F. (2004). Brand building literature review. ESADE, Universidad Ramon Llull.

Jones, R. (2005). Developing a stakeholder model for brand equity. Journal of Brand Management, 13(1), 10-32. 
Kakabadse, N., Rozuel, C., \& Lee-Davies, L. (2005). Corporate social responsibility a stakeholder approach: a conceptual review. International Journal of Business Governance and Ethics, 1(4), 277-302.

Kam, K. S., Fung, \& King, C. (2010). When experience matters: building, measuring hotel brand equity. International Journal of Contemporary Hospitality Management, 22(5), 589608 .

Kapferer, J-N. (2005). The new strategic brand management. London: Kogan Press.

Keller, K. L. (1993). Conceptualizing, measuring and managing customer-based brand equity. Journal of Marketing, 57, 1-22.

(2000). Building and managing corporate brand equity. In: Schultz, Majzen, M.J.Hatch and M. Larsen, Expressive Organization: Linking Identity, Reputation and the Corporate Brand. New York: The Oxford University Press.

. (2003). Strategic brand management: building, measuring and managing brand equity. Upper Saddle River, NJ: Pearson Education.

Keller, K. L. \& Lehmann, D. R. (2006). Brand and branding: research findings and future priorities. Marketing Science, 25(6), 740-759.

Kotler, P., \& Keller, K. L. (2006). Administração de marketing. (12.ed.) São Paulo: Pearson Prentice Hall.

Mitchell, R. K., Agle, B. R., \& Wood, D. J. (1997). Toward a theory of stakeholder identification and salience: defining the principle of who and what really counts. Academy of Management Review, 22, 853-886.

Porter, M. E. (2004). Estratégia competitiva. (2a ed.), Rio de Janeiro: Elsevier.

Preble, J. F. (2005). Toward a comprehensive model of stakeholder management. Business and Society Review, 110(4), 407-431.

Raggio, R. D., \& Leone, R. P. (2006). The theoretical separation of brand equity and brand value. Fisher College of Business.

Raupp, F. \& Beuren, I. M. (2006). Metodologia da pesquisa aplicável às ciências sociais. In. Beuren, Ilse Maria. (Org). Como elaborar trabalhos monográficos em contabilidade. (3.ed.) São Paulo: Atlas.

Shamma, H. M., \& Hassan, S. (2011). Integrating product and corporate brand equity into total brand equity measurement. International Journal of Marketing Studies, 3(1), 11-20.

Torres, A., Tammo, H. A. B., \& Josep, A.T. (2010) Generating global brand equity through corporate social responsibility to key stakeholders. Business Economic Series, Universidad Carlos III de Madrid. Recuperado em 28 abril, 2016, de http://earchivo.uc3m.es/bitstream/10016/9314/1/indemwp10_04.pdf.

Wang, H. M. D. \& Bezawada, R. (2011). Global brand equity, multi stakeholder relations, and firm performance. American Marketing Association Publication, Summer. 
Wood, L. (2000). Brands and brand equity: definition and management. Management Decision, 38(9), 662-669.

Yin, R. K. (2001). Estudo de caso: planejamento e métodos. Trad. Daniel Grassi, (2.ed.) Porto Alegre: Bookman. 